\title{
Mobile MAX-DOAS observations of tropospheric trace gases
}

\author{
T. Wagner ${ }^{1}$, O. Ibrahim ${ }^{1}$, R. Shaiganfar ${ }^{1}$, and U. Platt ${ }^{2}$ \\ ${ }^{1}$ Max-Planck-Institute for Chemistry, Mainz, Germany \\ ${ }^{2}$ Institute for Environmental Physics, University of Heidelberg, Germany \\ Received: 25 September 2009 - Published in Atmos. Meas. Tech. Discuss.: 2 November 2009 \\ Revised: 18 January 2010 - Accepted: 19 January 2010 - Published: 3 February 2010
}

\begin{abstract}
From Multi-Axis- (MAX-) DOAS observations, information on tropospheric trace gases close to the surface and up to the free troposphere can be obtained. Usually MAX-DOAS observations are performed at fixed locations, which allows to retrieve the diurnal variation of tropospheric species at that location. Alternatively, MAX-DOAS observations can also be made on mobile platforms like cars, ships or aircrafts. Then, in addition to the vertical (and temporal) distribution, also the horizontal variation of tropospheric trace gases can be measured. Such information is important for the quantitative comparison with model simulations, study of transport processes, and for the validation of tropospheric trace gas products from satellite observations. However, for MAX-DOAS observations from mobile platforms, the standard analysis techniques for MAX-DOAS observations can usually not be applied, because the probed airmasses can change rapidly between successive measurements. In this study we introduce a new technique which overcomes these problems and allows the exploitation of the full information content of mobile MAX-DOAS observations. Our method can also be applied to MAX-DOAS observations made at fixed locations in order to improve the accuracy especially in cases of strong winds. We apply the new technique to MAX-DOAS observations made during an automobile trip from Brussels to Heidelberg.
\end{abstract}

\section{Introduction}

In recent years Multi-AXis-Differential Optical Absorption Spectroscopy (MAX-DOAS) observations have become a widely and successfully used technique for the remote sensing of tropospheric trace gases and aerosols (Leser et al., 2003; Van Roozendael et al., 2003; Wittrock et al., 2003;

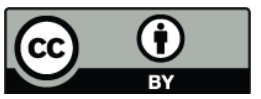

Correspondence to: T. Wagner (thomas.wagner@mpch-mainz.mpg.de)
Hönninger et al., 2004a, b; Sinreich et al., 2005; Heckel et al., 2005; Frieß et al., 2006; Fietkau et al., 2007; Theys et al., 2007; Wagner et al., 2004, 2007a, b, 2009; Irie et al., 2008). MAX-DOAS instruments observe scattered sun light under different (mostly slant) viewing angles, providing high sensitivity to tropospheric trace gases and aerosols. One basic prerequisite for the accurate analysis of tropospheric species from MAX-DOAS observations is the assumption that the same air parcels are probed by the different viewing directions (different elevation angles, and relative azimuth angles). This assumption is typically quite well fulfilled, but can in principle be violated by two main causes: First, trace gases can be located at high altitudes above the instrument and are "seen" by the instrument at different horizontal distances depending on the viewing geometry. Second, many MAX-DOAS instruments scan different elevation angles sequentially and since the probed air masses at the measurement location can change due to transport according to the prevailing wind conditions, the column densities recorded at the different elevation angles may actually belong to different air masses. For MAX-DOAS observations at fixed locations both aspects can usually be neglected, because typically the highest trace gas concentrations are located close to the surface. Thus the horizontal distances of the probed air masses from the instrument for different viewing angles are typically rather small (e.g. a trace gas located at $100 \mathrm{~m}$ altitude is observed by an elevation angle of $3^{\circ}$ at a horizontal distance of about $2 \mathrm{~km}$ ). In addition, since the typical temporal resolution of MAX-DOAS observations is of the order of minutes, the distances which the air masses move between successive observations is usually small. Assuming a wind speed of $2 \mathrm{~m} / \mathrm{s}$, air masses will travel only about $120 \mathrm{~m}$ within a minute, which is much shorter than the typical absorption path lengths of MAX-DOAS observations in the troposphere.

Apart from MAX-DOAS observations made at fixed locations, they can also be made from fast moving platforms like aircrafts or cars (Heue et al., 2005; Wang et al., 2005, 2006; Bruns et al., 2006; Johansson et al., 2008, 2009;

Published by Copernicus Publications on behalf of the European Geosciences Union. 


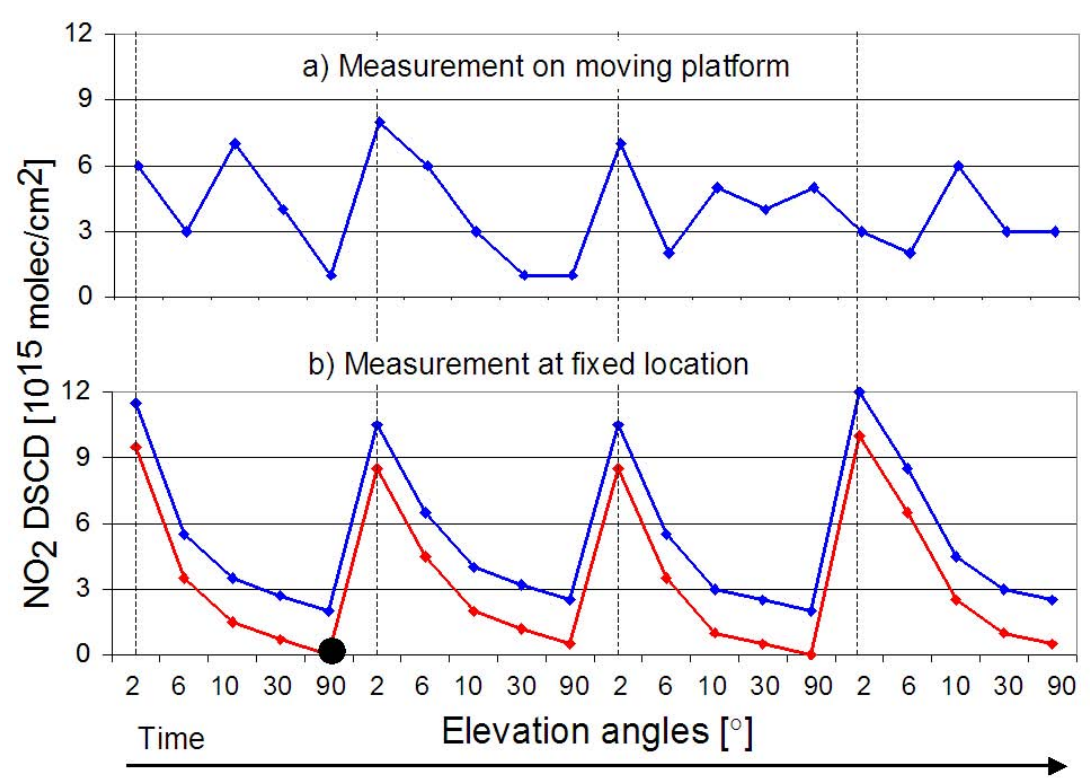

Fig. 1. Typical examples of trace gas slant column densities (DSCD ${ }_{\text {meas }}$, see Eq. 2$)$ obtained for 4 successive elevation angle sequences $\left(2^{\circ}\right.$, $6^{\circ}, 10^{\circ}, 30^{\circ}, 90^{\circ}$ ). Bottom: results for MAX-DOAS observations made at a fixed location. The highest SCDs are observed for the lowest elevation angles. The red line indicates results analysed with the $90^{\circ}$ spectrum of the first sequence as Fraunhofer reference (thus DSCD $\mathrm{D}_{\text {meas }}$ of the first sequence directly yield $\mathrm{DSCD}_{\text {trop }}$, see Eq. 3). The blue line indicates results analysed with a Fraunhofer spectrum from another day, and DSCD trop can be obtained using Eq. 4. Top: results for MAX-DOAS observations on mobile platforms. No clear dependence of the $\mathrm{SCD}_{\text {meas }}$ on elevation angle is found, because the trace gas concentration changes with location.

Dix et al., 2009), typically travelling at $10 \mathrm{~s}$ to $100 \mathrm{~s}$ of meter per second. Such observations have a high potential for the investigation of tropospheric trace gas distributions. They can e.g. yield information on the spatial distribution of emission sources. In combination with wind fields, even the total trace gas fluxes across the vertical planes above the driving route can be determined (see e.g. Volk, 2008; Johansson et al., 2009). From this technique the total emissions of emission sources can be retrieved if mobile MAX-DOAS observations are performed on closed routes around these sources (Volk, 2008; Ibrahim, 2009). In addition to these applications, MAX-DOAS observations are ideal means for the validation of model simulations and satellite observations (Brinksma et al., 2008; Celarier et al., 2008). Satellite observations of tropospheric trace gases usually average over very large volumes (ground pixel in the order of several hundreds of square kilometres). Knowledge on the spatial variability within the satellite ground pixel therefore is a fundamental prerequisite for the quantitative validation of satellite observations of tropospheric species.

In contrast to MAX-DOAS observations at fixed locations, mobile MAX-DOAS observations are subject to particular uncertainties, which are caused by the rapid change of air masses probed along the driving route. For these platforms, the usual way of the MAX-DOAS data analysis (see below) can lead to large errors, in extreme cases even 'negative concentrations' might be retrieved.
Here we propose a new method for the accurate determination of the integrated tropospheric trace gas concentration (the so called vertical column density, VCD) from mobile MAX-DOAS observations. The only requirement of the technique is that a sufficient number (typically $>$ about 20) of successive MAX-DOAS elevation angle scanning sequences (see Fig. 1) are performed within a continuous measurement period. A continuous measurement period is defined here as a period, during which the instrumental properties do not substantially change (e.g. as a result of a temperature change of the detector). This is typically fulfilled for measurements carried out during one day or part of a day (for very stable instrument conditions also longer periods are possible). Our method allows to exploit the full potential of mobile MAXDOAS observations: it provides the maximum spatial resolution corresponding to the driving speed and the temporal resolution of the measurements. At the same time our method assures that the retrieved data is not affected by systematic biases.

The paper is structured as follows: in Sect. 2 the usual method for the retrieval of tropospheric species (trace gases and aerosols) from MAX-DOAS observations is reviewed and resulting problems for the application to observations from mobile platforms are discussed. Section 3 introduces a new retrieval technique which overcomes these problems. In Sect. 4 the new technique is applied to MAX-DOAS observations made during a car journey from Brussels to Heidelberg. Sect. 5 presents conclusions and outlook. 


\section{Tropospheric trace gas retrieval from MAX-DOAS observations}

MAX-DOAS instruments observe scattered sunlight from various viewing directions. While the sensitivity to stratospheric trace gas absorptions is almost independent on the viewing direction (e.g. Hönninger and Platt, 2002; Leser et al., 2003; Bobrowski et al., 2003; van Roozendael et al., 2003; Wittrock et al., 2004; Hönninger et al., 2004; Heckel et al., 2004; Wagner et al., 2004, 2007a; Frieß et al., 2006; Fietkau et al., 2007; Theys et al., 2007), the sensitivity for tropospheric trace gases and aerosols depends strongly on the elevation angle (and to a lesser degree also on the relative azimuth angle, i.e. the difference of the azimuth angles of the telescope and the sun). Thus by combining observations made at different elevation angles, information on the tropospheric abundance of trace gases and aerosols can be retrieved (Hönninger and Platt, 2002). Typically a twostep retrieval is applied. In the first step the observed spectra are analysed using Differential Optical Absorption Spectroscopy (DOAS) yielding the integrated trace gas concentrations along the atmospheric light paths, the so called slant column densities (SCD). In the second step a set of trace gas SDCs observed under different viewing directions is converted into more universal quantities, like height profiles of the trace gas concentration (or aerosol extinction) or the tropospheric trace gas VCD (or total aerosol optical depth).

Tropospheric profile retrievals are mainly based on observations from low elevation angles (below $\sim 20^{\circ}$ ) and can yield several pieces of information, with the highest vertical resolution close to the surface (e.g. Hönninger and Platt, 2002; Heckel et al., 2005). They can usually be performed only under cloud free conditions.

The vertically integrated tropospheric concentration (tropospheric VCD) is retrieved from MAX-DOAS observations from higher elevation angles (above $\sim 10^{\circ}$ ), and in the simplest case (e.g. without aerosols and clouds present, see also Sect. 2.3) the atmospheric light paths can be geometrically approximated (Andreas Richter, personal communication, 2005; Brinksma et al., 2008; Celarier et al., 2008). Using this method, the retrieval of tropospheric VCDs is possible even in the presence of clouds, at least for the trace gas concentrations below the cloud base. The tropospheric VCD contains information on the integrated trace gas concentration for atmospheric layers close to the surface. Above about $2 \mathrm{~km}$, the measurement sensitivity gradually decreases, depending mainly on wavelength, elevation angle and the atmospheric aerosol load (for details see e.g. Wagner et al., 2007a).

In this paper we concentrate on the retrieval of tropospheric trace gas VCDs from MAX-DOAS observations. In principle, also vertical profiles of aerosols and trace gases could be retrieved from mobile MAX-DOAS observations, as long as the time for an elevation scanning sequence is small compared to the variation of the atmospheric concentration with time (depending on the spatial gradients and the driving speed). For car measurements, in addition the view at low elevation angles (i.e. at a few degrees) is often blocked by obstacles like buildings or trees. For airborne and ship MAX-DOAS observations (Leser et al., 2003; Heue et al., 2005; Wang et al., 2005, 2006; Bruns et al., 2006; Dix et al., 2009), also viewing angles close to the horizon might be used. For ship MAX-DOAS observations profile retrievals should in general be possible. For airborne MAX-DOAS observations, profiles might be retrieved outside from polluted regions or at high altitudes.

\subsection{Basic quantities retrieved from MAX-DOAS observations}

The measured spectra are analysed using the DOAS method (Platt and Stutz, 2008). To the (logarithm of the) measured spectra several trace gas cross sections as well as a Ring spectrum (Grainger and Ring, 1962), a Fraunhofer reference spectrum, and a low order polynomial are fitted by means of a least squares fitting routine (Stutz and Platt, 1996) (for more details see also Sect. 4.2). The output of the spectral analysis is the measured SCD, the integrated trace gas concentration along the light path through the atmosphere. It is the sum of the partial SCDs in the troposphere and the stratosphere:

$\mathrm{SCD}_{\text {meas }}=\mathrm{SCD}_{\text {trop }}+\mathrm{SCD}_{\text {strat }}$

Since the Fraunhofer reference spectrum also contains atmospheric trace gas absorptions, the result of the DOAS analysis represents the difference between the SCDs of the measured spectrum $\left(\mathrm{SCD}_{\text {meas }}\right)$ and that of the Fraunhofer reference spectrum $\left(\mathrm{SCD}_{\mathrm{ref}}\right)$; this difference is usually referred to as differential SCD (DSCD):

$\mathrm{DSCD}_{\text {meas }}=\mathrm{SCD}_{\text {meas }}-\mathrm{SCD}_{\text {ref }}$

While in principle, for the Fraunhofer reference spectrum any measured spectrum can be chosen, usually a spectrum with small trace gas absorption is selected, e.g. measured in zenith direction (elevation angle $\alpha=90^{\circ}$ ) at noon.

For most MAX-DOAS observations where the stratospheric VCD is comparable to or smaller than the tropospheric VCD (one exception is the observation of ozone), it can be assumed that the stratospheric absorption is the same in all spectra taken during one elevation sequence. Thus, if the Fraunhofer spectrum is taken within a small temporal distance from the measurement (e.g. from the same elevation sequence, see Fig. 1), it can be assumed that the $\mathrm{SCD}_{\text {strat }}$ of both spectra cancel each other and Eq. 2 can be written as:

$$
\begin{aligned}
\operatorname{DSCD}_{\text {meas }}(\alpha) & =\operatorname{SCD}_{\text {trop }}(\alpha)+\operatorname{SCD}_{\text {strat }}-\operatorname{SCD}_{\text {trop }}\left(90^{\circ}\right)-\mathrm{SCD}_{\text {strat }} \\
& =\operatorname{SCD}_{\text {trop }}(\alpha)-\mathrm{SCD}_{\text {trop }}\left(90^{\circ}\right)
\end{aligned}
$$

Here $\operatorname{DSCD}_{\text {trop }}(\alpha)$ is the tropospheric DSCD for the elevation angle $\alpha$; it is the basic quantity derived from MAXDOAS observations. $\operatorname{DSCD}_{\text {trop }}(\alpha)$ contains only tropospheric absorption signals and can be determined by simple subtraction of the SCDs of two measurements. 
Equation 3 also holds, if instead of the total SCDs (which are usually not known) the respective DSCDs (see Eq. 2) are used. Of course, this substitution is only possible if both spectra were analysed using the same Fraunhofer reference spectrum (see Fig. 1, bottom). Equation 3 then becomes:

$$
\operatorname{DSCD}_{\text {trop }}(\alpha)=\operatorname{DSCD}_{\text {meas }}(\alpha)-\operatorname{DSCD}_{\text {meas }}\left(90^{\circ}\right)
$$

In the most simple case, the zenith spectrum from the same elevation sequence is used as Fraunhofer reference spectrum (Fig. 1, bottom, red line, first sequence) and $\operatorname{DSCD}_{\text {meas }}\left(90^{\circ}\right)$ becomes zero. Then Eq. 4 reduces to:

$\operatorname{DSCD}_{\text {trop }}(\alpha)=\operatorname{DSCD}_{\text {meas }}(\alpha)$

(where $\mathrm{DSCD}_{\text {meas }}$ is determined according to Eq. 2). Therefore, for MAX-DOAS retrievals, often a Fraunhofer reference spectrum from the same elevation sequence is chosen. In such cases, also the fit residual is small, because of the small time difference between both spectra.

Nevertheless, in some cases, it can be more convenient to use only a single Fraunhofer reference spectrum for a larger set of MAX-DOAS spectra, because it simplifies the analysis. In this study, we use a single Fraunhofer reference spectrum for the analyses of all measurements made during a single day (Fig. 1, bottom, blue line).

\subsection{Determination of the tropospheric vertical column density}

Usually the trace gas SCD obtained from the spectral analysis is converted into a vertical column density (VCD). For that purpose, a so called air mass factor (AMF) is applied (Noxon et al., 1979; Solomon et al., 1987; Marquard et al., 2000), which is defined as the ratio of the (total) SCD and (total) VCD:

$\mathrm{VCD}=\frac{\mathrm{SCD}}{\mathrm{AMF}}$

The AMF is usually derived from numerical simulations of the atmospheric radiative transfer (e.g. Solomon et al., 1987; Perliski and Solomon, 1993). For the analysis of MAXDOAS observations we are mainly interested in the tropospheric vertical column density $\mathrm{VCD}_{\text {trop }}$, and Eq. 6 can be adapted to tropospheric quantities:

$\operatorname{VCD}_{\text {trop }}=\frac{\operatorname{SCD}_{\text {trop }}(\alpha)}{\operatorname{AMF}_{\text {trop }}(\alpha)}$

Combining Eqs. 7 and 3 we get:

$$
\begin{aligned}
& \frac{\operatorname{SCD}_{\text {trop }}(\alpha)}{\mathrm{AMF}_{\text {trop }}(\alpha)}=\frac{\mathrm{DSCD}_{\text {trop }}(\alpha)+\operatorname{SCD}_{\text {trop }}\left(90^{\circ}\right)}{\mathrm{AMF}_{\text {trop }}(\alpha)}=\mathrm{VCD}_{\text {trop }} \\
& =>\mathrm{DSCD}_{\text {trop }}(\alpha)=\mathrm{AMF}_{\text {trop }}(\alpha) \cdot \mathrm{VCD}_{\text {trop }}-\mathrm{AMF}_{\text {trop }}\left(90^{\circ}\right) \cdot \mathrm{VCD}_{\text {trop }} \\
& =>\mathrm{VCD}_{\text {trop }}=\frac{\mathrm{DSCD}_{\text {trop }}(\alpha)}{\mathrm{AMF}_{\text {trop }}(\alpha)-\mathrm{AMF}_{\text {trop }}\left(90^{\circ}\right)}=\frac{\operatorname{DSCD}_{\text {trop }}(\alpha)}{\mathrm{DAMF}_{\text {trop }}(\alpha)}
\end{aligned}
$$

Thus, with the use of $\mathrm{DAMF}_{\text {trop }}(\alpha)=\mathrm{AMF}_{\text {trop }}(\alpha)-\mathrm{AMF}_{\text {trop }}$ $\left(90^{\circ}\right)$, the tropospheric $\mathrm{VCD}$ can be directly derived from the tropospheric $\operatorname{DSCD}_{\text {trop }}(\alpha)$ (see Eqs. 4, 5). With the assumption that the tropospheric trace gas concentration stays constant between the observations of both spectra (made at elevation angles $\alpha$ and $90^{\circ}$ ), this equation becomes the basis for the determination of the tropospheric trace gas VCDs from MAX-DOAS observations.

\subsection{Geometrical approximation for ground based observations}

For ground based (Auto-) MAX-DOAS observations, in many cases (using e.g. elevation angles larger than $\sim 10^{\circ}$ and small aerosol extinction) it is possible to approximate the tropospheric AMF by a geometrical AMF (Hönninger and Platt, 2002; Andreas Richter, personal communication, 2005; Brinksma et al., 2008; Celarier et al., 2008):

$\mathrm{AMF}_{\text {trop }} \approx \frac{1}{\sin (\alpha)}$

Then Eq. 8 becomes:

$\mathrm{VCD}_{\text {trop }}=\frac{\operatorname{DSCD}_{\text {trop }}(\alpha)}{\frac{1}{\sin (\alpha)}-1}$

A particularly convenient choice for the elevation angle might be $30^{\circ}$, since $1 / \sin \left(30^{\circ}\right)=2$, and thus the DSCD for $30^{\circ}$ elevation angle directly yields the tropospheric VCD. However, other choices of $\alpha$ are also possible (see below).

The geometric approximation of the tropospheric AMF can be used in many situations. However, for observations at low elevation angles large deviations from the true tropospheric AMF can occur. Even for retrievals using high elevation angles, large errors can occur in the presence of high aerosol loads. Then, also the relative azimuth angle between the viewing direction and the sun can become important. In such cases more realistic AMF derived from radiative transfer simulations have to be used in combination with Eq. 8 . Also for airborne MAX-DOAS observations usually AMF from detailed radiative transfer modelling have to be applied. Only in cases without clouds and high surface reflectance, geometrical approximations like in Eq. 9 might be also used for airborne MAX-DOAS observations.

\subsection{Complications for MAX-DOAS observations from mobile platforms}

The prerequisite for the application of Eqs. 8 and 10 is that during the time of one elevation scan (or at least between the observations at low elevation $\alpha$ and $90^{\circ}$ elevation) the tropospheric trace gas field does not change significantly. For observations at fixed locations, this assumption is usually well fulfilled (at least for small wind speeds and short measurement times). 
The situation becomes quite different for MAX-DOAS observations made from mobile platforms like airplanes or cars. Because of the movement of the platform, during one measurement sequence the trace gas concentrations can largely change and the sequence of retrieved trace gas DSCDs does not show a "regular" dependence on the elevation angle (Fig. 1, top). In extreme cases, even negative $\mathrm{VCD}_{\text {trop }}$ might be obtained using the method described in Sect. 2.2 (Eqs. 8, 10). Ways to minimise this problem could in principle be to reduce the time for an individual measurement or to perform simultaneous measurements at $\alpha$ and $90^{\circ}$. However, in the first case a reduction also decreases the signal to noise ratio, while in the second case spectra have to be taken by different instruments.

\subsection{Alternative ways for the determination of the tropospheric VCD}

One solution to overcome the problems for MAX-DOAS observations from mobile platforms could be to use a single Fraunhofer reference spectrum (e.g. taken at $90^{\circ}$ elevation and at low solar zenith angle) for the analysis of the whole measurement sequence along the driving or flight route (see e.g. Herman et al. (2009). Then the actual gradients of the trace gas distribution could be well resolved (according to the temporal resolution of the measurement and the driving speed). The tropospheric VCD can then be obtained from a single observation in the following way (using Eqs. 1 and 7):

$$
\begin{aligned}
\mathrm{VCD}_{\text {trop }} & =\frac{\operatorname{SCD}_{\text {meas }}(\alpha)-\operatorname{SCD}_{\text {strat }}(\mathrm{SZA})}{\mathrm{AMF}_{\text {trop }}(\alpha)} \\
& =\frac{\mathrm{DSCD}_{\text {meas }}(\alpha)+\operatorname{SCD}_{\text {ref }}-\mathrm{SCD}_{\text {strat }}(\mathrm{SZA})}{\operatorname{AMF}_{\text {trop }}(\alpha)}
\end{aligned}
$$

(where SZA denotes the solar zenith angle). However, the application of Eq. 11 requires the knowledge of $\mathrm{SCD}_{\text {ref }}$ and $\mathrm{SCD}_{\text {strat }}$ (SZA), which are usually not known. Thus only in cases with a) rather high tropospheric trace gas concentrations and with b) the possibility to measure a Fraunhofer reference spectrum outside strongly polluted regions, Eq. 11 could be applied with acceptable errors (caused by the uncertainty of the estimation of $\mathrm{SCD}_{\text {ref }}$ and $\mathrm{SCD}_{\text {strat }} \mathrm{SZA}$ ). For observations with small and/or spatially homogenous tropospheric trace gas concentrations, Eq. 11 can yield very large systematic errors.

While $\mathrm{SCD}_{\text {ref }}$ is a constant (because a single Fraunhofer reference spectrum was used), $\mathrm{SCD}_{\text {strat }}$ (SZA) usually depends on the solar zenith angle. This dependence is weak for small SZA, but might not be neglected for high SZA (> about $80^{\circ}$ ). We will refer to the difference of the two unknowns $\mathrm{SCD}_{\text {ref }}$ and $\mathrm{SCD}_{\text {strat }}(\mathrm{SZA})$ as $\mathrm{DSCD}_{\text {offset }}(\mathrm{SZA})$ in the following:

$\mathrm{DSCD}_{\text {offset }}(\mathrm{SZA})=\mathrm{SCD}_{\text {ref }}-\mathrm{SCD}_{\text {strat }}(\mathrm{SZA})$
In this study, we propose a method to determine $\mathrm{DSCD}_{\text {offset }}$ (SZA) from the MAX-DOAS observations themselves. This method allows to retrieve the correct absolute values of the tropospheric VCD using Eq. 11. In the first step, the expressions for $\mathrm{VCD}_{\text {trop }}$ in Eqs. 8 and 11 are set equal:

$$
\begin{aligned}
& \frac{\operatorname{DSCD}_{\text {meas }}(\alpha)-\mathrm{DSCD}_{\text {meas }}\left(90^{\circ}\right)}{\mathrm{AMF}_{\text {trop }}(\alpha)-\mathrm{AMF}_{\text {trop }}\left(90^{\circ}\right)} \\
= & \frac{\operatorname{DSCD}_{\text {meas }}(\alpha)+\operatorname{SCD}_{\text {ref }}-\operatorname{SCD}_{\text {strat }}(\operatorname{SZA})}{\mathrm{AMF}_{\text {trop }}(\alpha)}
\end{aligned}
$$

This equation can be solved for $\mathrm{DSCD}_{\text {offset }}(\mathrm{SZA})$ as defined in $\mathrm{Eq} 12$ :

$$
\begin{aligned}
& \operatorname{DSCD}_{\text {offset }}(\mathrm{SZA}) \\
= & \frac{\mathrm{AMF}_{\text {trop }}\left(90^{\circ}\right) \cdot \mathrm{DSCD}_{\text {meas }}(\alpha)-\mathrm{AMF}_{\text {trop }}(\alpha) \cdot \operatorname{DSCD}_{\text {meas }}\left(90^{\circ}\right)}{\operatorname{AMF}_{\text {trop }}(\alpha)-\operatorname{AMF}_{\text {trop }}\left(90^{\circ}\right)}
\end{aligned}
$$

Thus DSCD $_{\text {offset }}(\mathrm{SZA})$ can in principle be derived from a single pair of measurements $\operatorname{DSCD}_{\text {meas }}(\alpha)$ and $\operatorname{DSCD}_{\text {meas }}$ $\left(90^{\circ}\right)$ from one elevation sequence. However, as mentioned above, due to the movement of the mobile platforms different air masses are probed by successive measurements and large deviations of the derived $\mathrm{DSCD}_{\text {offset }}(\mathrm{SZA})$ from its true value can occur if only two measurements are used.

One strategy to overcome this problem is to include more than two measurements in the determination of $\mathrm{DSCD}_{\text {offset }}$ (SZA). The deviations of $\mathrm{DSCD}_{\text {offset }}$ (SZA) from the true value occur randomly, because the probabilities that the trace gas concentration was either higher or lower during the first measurement are the same. Thus the average of $\mathrm{DSCD}_{\text {offset }}$ (SZA) derived from a large set of measurements should converge against the true value. It should, however, be noted that for observations of localised plumes this assumption could be violated. Such measurements can be identified and should be removed from the determination of DSCD $_{\text {offset }}$ (SZA) (see Sect. 4.3).

One remaining problem is that $\mathrm{DSCD}_{\text {offset }}$ (SZA) depends on the solar zenith angle. Thus, it is not possible to just average all values for DSCD $_{\text {offset }}$ (SZA) derived from the MAXDOAS observations. However, since DSCD $_{\text {offset }}(\mathrm{SZA})$ is a smooth function of the SZA, it is possible to fit the time series of calculated $\mathrm{DSCD}_{\text {offset }}$ (SZA) by a low order polynomial (e.g. $\mathrm{P}(x)=a_{0}+a_{1} x+a_{2} x^{2}$ ). Since the SZA varies smoothly with time, the polynomial could be selected as function of either SZA or time. In most cases, the latter might be more convenient, because then the calculation of the SZA can be omitted. If $t_{i}$ indicates the time between the two selected measurements from one elevation sequence $i$, the time series

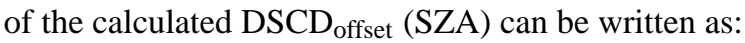

$$
\begin{aligned}
& \operatorname{DSCD}_{\text {offset }}\left(t_{i}\right) \\
= & \frac{\operatorname{AMF}_{\text {trop }}\left(90^{\circ}\right) \cdot \operatorname{DSCD}_{\text {meas }}\left(\alpha, t_{i}\right)-\operatorname{AMF}_{\text {trop }}(\alpha) \cdot \operatorname{DSCD}_{\text {meas }}\left(90^{\circ}, t_{i}\right)}{\operatorname{AMF}_{\text {trop }}\left(\alpha, t_{i}\right)-\operatorname{AMF}_{\text {trop }}\left(90^{\circ}, t_{i}\right)}
\end{aligned}
$$


The error of the fitted polynomial will decrease with an increasing number of observations: assuming e.g. an error of $50 \%$ for an individual $\mathrm{DSCD}_{\text {offset }}\left(t_{i}\right)$, including a measurement sequence of 20 data points will result in a remaining error of only about $11 \%$. The fitted polynomial then represents the best guess for $\operatorname{DSCD}_{\text {offset }}(t)$ and can be inserted into Eq. 11. In this way one can derive a consistent time series of tropospheric trace gas VCDs essentially without errors introduced by the spatio-temporal variations of the trace gas field. Moreover, due to the combination of Eqs. 8 and 11 the derived tropospheric VCD has no remaining bias (besides any uncertainties caused by the errors of the tropospheric AMFs).

Of course, Eq. 11 (like Eqs. 14, 15) can in principle be separately applied to measurements made at individual elevation angles $\alpha$ (including zenith viewing direction). However, for the choice of $\alpha$, several aspects should be considered. The highest sensitivity for tropospheric trace gases is usually found for elevation angles close to the horizon. On the other hand, also the uncertainties of the AMF calculation is rather high for such elevation angles. For Auto-MAX-DOAS, also the probability of obstacles in the field of view increases with decreasing elevation angle.

Good compromises are probably elevation angles of about $+20^{\circ}$ for Auto-MAX-DOAS and $-20^{\circ}$ (below the aircraft) for airborne MAX-DOAS observations. Then, for AutoMAX-DOAS observations also the geometric approximation can be used. For these elevation angles, the sensitivity for tropospheric species is about more than twice of that for zenith or nadir viewing direction.

It might be useful to make measurements at more than one slant elevation angle. Then the comparison of the tropospheric VCDs derived from the different elevation angles (using Eq. 11) can yield valuable information on the accuracy of the retrieval, e.g. on the validity of the geometric approximation (Eqs. 9, 10), see below.

\section{Application to measurement data}

In this section, the above introduced method is applied to Auto-MAX-DOAS observations made on a car journey from Brussels (Belgium) to Heidelberg (Germany) on 5 September 2006. The measurements were made with a so called MiniMAX-DOAS instrument mounted on the car top. During the journey more than 1000 individual spectra were recorded, providing ideal prerequisites for the application of the new method.

\subsection{Instrumental set-up}

The Mini-MAX-DOAS instrument is a fully automated, light weighted spectrometer $(13 \mathrm{~cm} \times 19 \mathrm{~cm} \times 14 \mathrm{~cm})$ designed for the spectral analysis of scattered sunlight (e.g. Sinreich et al., 2005). It consists of a sealed metal box containing the entrance optics, a fibre coupled spectrograph and the con- trolling electronics. The spectrograph is cooled by a thermoelectric element. A stepper motor adjusted outside the box rotates the whole instrument to control the elevation of the viewing angle (angle between the horizontal and the viewing direction). The entrance optics consists of a quartz lens of focal length $f=40 \mathrm{~mm}$ coupled to a quartz fibre bundle which leads the collected light into the spectrograph (field of view is $\sim 1.2^{\circ}$ ). The light is dispersed by a crossed CzernyTurner spectrometer (USB2000, Ocean Optics Inc.) with a spectral resolution of $0.7 \mathrm{~nm}$ over a spectral range from 320 $460 \mathrm{~nm}$. A one-dimensional CCD (Sony ILX511, 2048 individual pixels) is used as detector. Before the signal is transferred to the 12 bit analog-to-digital converter, an electronic offset is added. After conversion, the signal is digitally transmitted to a laptop computer via one USB cable and stored for subsequent analysis.

The whole spectrometer is cooled by a Peltier element to a stable temperature of $0^{\circ} \mathrm{C}$ in order to minimize changes in the optical properties of the spectrograph and to reduce the dark current.

For the mobile measurements the Mini-MAX-DOAS instrument was mounted on the top of a car (Auto-MAXDOAS) and was powered by the $12 \mathrm{~V}$ car battery. The telescope was alligned in forward direction. The rest of the setup was inside the car and both parts were connected via two electric cables. The measurements are controlled from a laptop using the DOASIS software (Kraus, 2006).

On 5 September 2006, measurements were carried out on the road between Brussels (Belgium) and Heidelberg (Germany). The distance between the two cities is $\sim 350 \mathrm{~km}$. The sequence of elevation angles was chosen to: $22^{\circ}, 22^{\circ}, 22^{\circ}$, $22^{\circ}, 40^{\circ}, 90^{\circ}$ and the duration of an individual measurement was about 20-25 s (containing between a few tens and more than 200 individual scans).

\subsection{Spectral retrieval}

In order to derive the trace gas SCDs, the measured spectra are analysed according to the DOAS method (Platt and Stutz, 2008 ) using the WinDOAS software (Fayt and van Roozendael, 2001). A wavelength range of 415-435 nm was selected for the analysis. Several trace gas absorption cross sections $\left(\mathrm{NO}_{2}\right.$ at $297 \mathrm{~K}$ (Vandaele et al., 1998), $\mathrm{H}_{2} \mathrm{O}$ at $300 \mathrm{~K}$ (Rothmann et al., 2005), $\mathrm{O}_{4}$ at $296 \mathrm{~K}$ (Greenblatt et al., 1990), and $\mathrm{O}_{3}$ at $243 \mathrm{~K}$ (Bogumil et al., 1999) as well as a Fraunhofer reference spectrum, a Ring spectrum (calculated from the Fraunhofer spectrum) and a polynomial of second order were included in the spectral fitting process. The wavelength calibration was performed using a high resolution solar spectrum (Kurucz et al., 1984). 


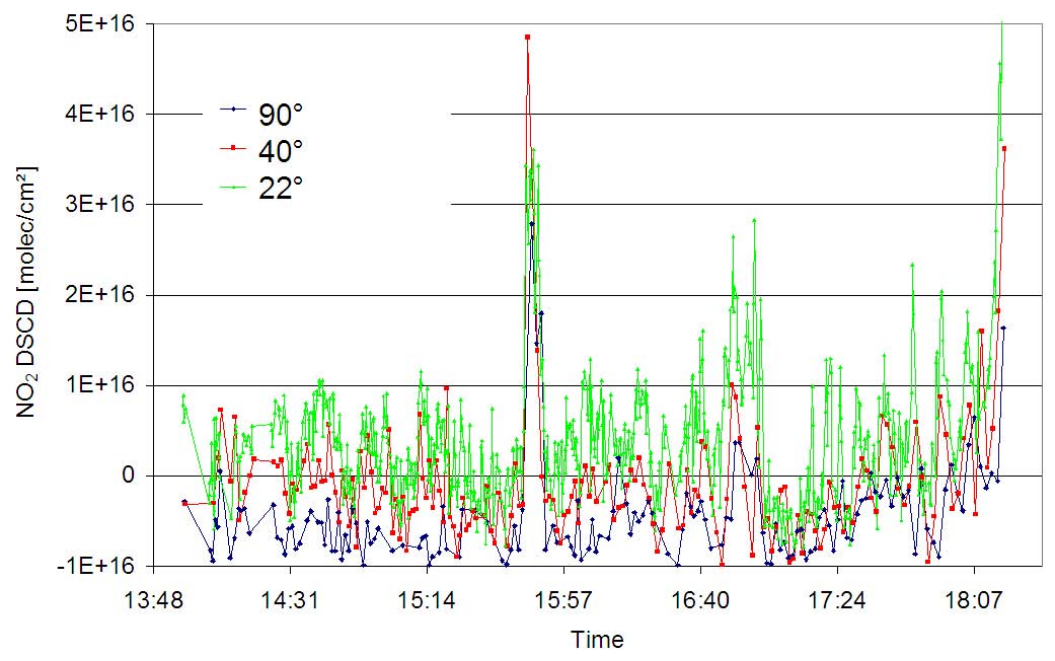

Fig. 2. $\mathrm{NO}_{2}$ DSCDs analysed from the spectra measured along the route between Brussels and Heidelberg. Results for all three elevation angles are shown. Especially for the higher elevation angles, also many negative values are found indicating that the $\mathrm{NO}_{2}$-absorption of the Fraunhofer reference spectrum is not negligible. As expected higher DSCDs are obtained for smaller elevation angles.

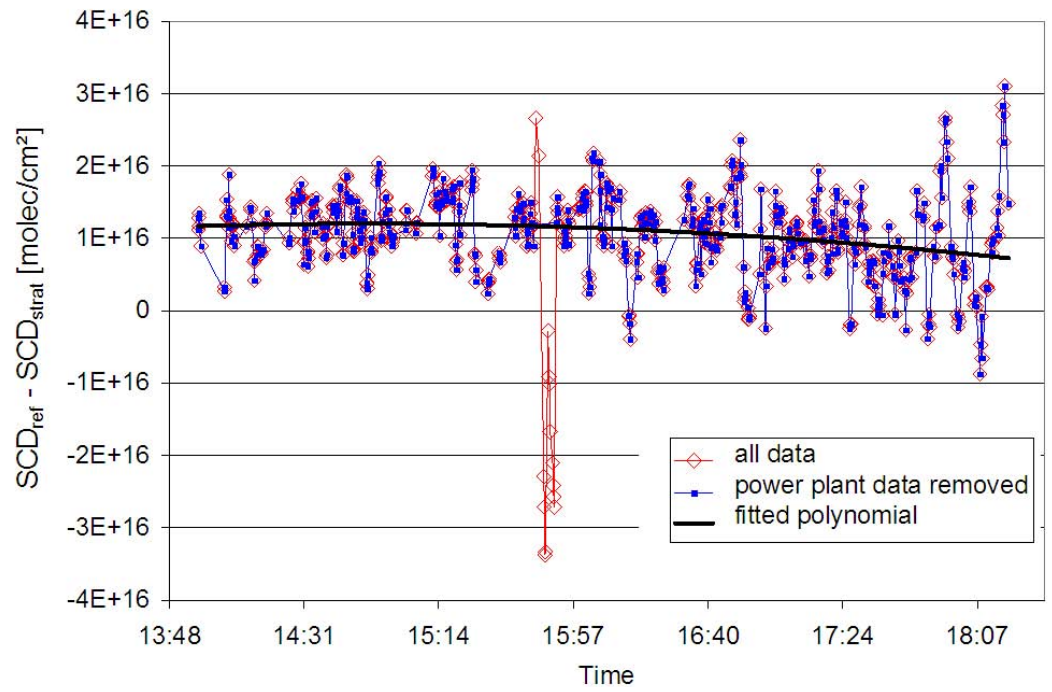

Fig. 3. $\mathrm{DSCD}_{\text {offset }}$ (see Eq. 15) plotted as a function of time (red points). For the observations close to the power plant, negative outliers are found, which are caused by the sharp gradients of the power plant plume (see text). For the fitting of a low order polynomial (black curve) representing $\operatorname{DSCD}_{\text {offset }}\left(\mathrm{t}_{i}\right)$ (see text), these data were excluded and only the blue points were used.

\subsection{Tropospheric vertical column densities}

For the retrieval of the tropospheric $\mathrm{NO}_{2}$ DSCDs, an individual Fraunhofer reference spectrum measured at $90^{\circ}$ elevation angle was used. Measurements at $22^{\circ}$ elevation angle were analysed to yield the time series of $\mathrm{NO}_{2} \mathrm{VCDs}$ along the route. As a consistency check, also for measurements at $40^{\circ}$ elevation angle tropospheric VCDs were evaluated.

In Fig. 2 the time series of $\mathrm{NO}_{2}$ DSCDs is shown including all three elevation angles. As expected according to Eq. 9, higher DSCDs are found for the lower elevation angles. The negative values indicate a substantial $\mathrm{NO}_{2}$ absorption in the Fraunhofer reference spectrum. The measured $\mathrm{NO}_{2}$ DSCDs already give a rough idea of the general variation of the tropospheric $\mathrm{NO}_{2}$ concentration along the route. High values are measured close to the Weisweiler power plant (Eschweiler, Germany) around 15:40. Elevated values are also found near the cities of Koblenz ( 16:50) and Mannheim (18:20).

In the next step of the analysis, the offset caused by the $\mathrm{NO}_{2}$ absorption in the Fraunhofer reference spectrum and the stratospheric absorption has to be determined. For that purpose $\mathrm{DSCD}_{\text {offset }}(t)$ is calculated according to Eq. 15 . In Fig. $3 \operatorname{DSCD}_{\text {offset }}(t)$ derived for the measurements at $22^{\circ}$ elevation angle is shown for the whole measurement series (red open diamonds). Besides the measurements close to the power plant, the $\operatorname{DSCD}_{\text {offset }}(t)$ shows a rather smooth 


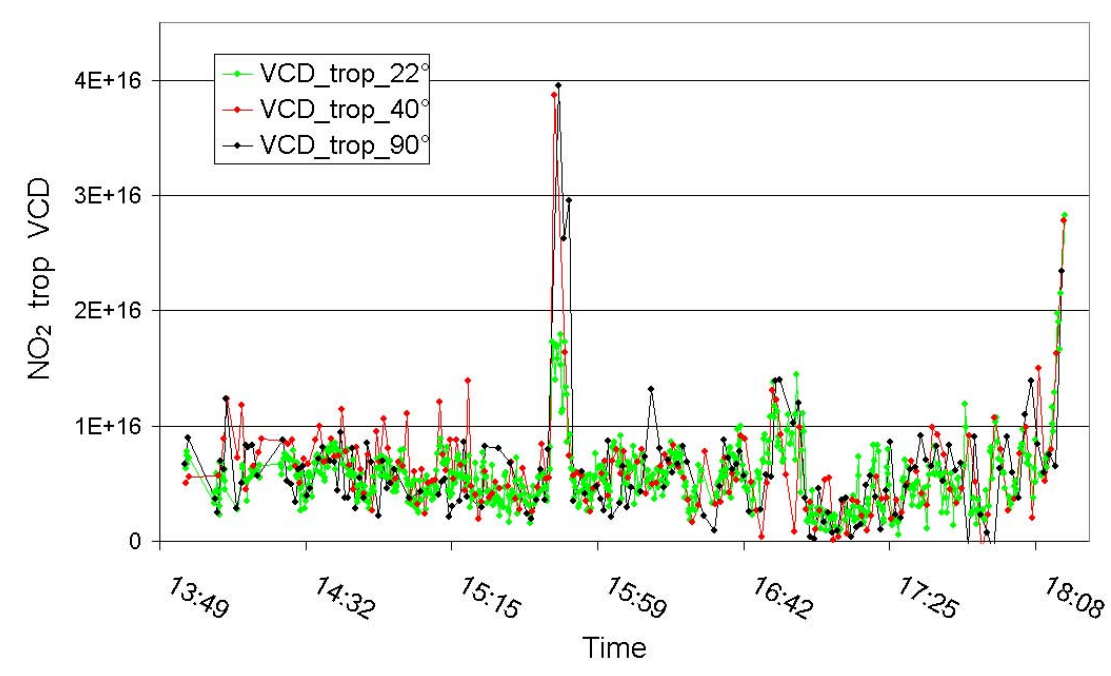

Fig. 4. The tropospheric VCDs of $\mathrm{NO}_{2}$ along the road from Brussels to Heidelberg calculated according Eq. 11 from observations at different elevation angles.

dependence on time as expected. The "outliers" during the measurements close to the power plant are caused by the fact that for the respective $90^{\circ}$ spectrum $\left(\operatorname{DSCD}_{\text {meas }}\left(90^{\circ}, t\right)\right.$, see Eq. 15) almost the same DSCD is found as for the $22^{\circ}$ spectrum (see Fig. 2). This indicates that the $\mathrm{NO}_{2}$ plume of the power plant was confined to a rather small volume, which was (partly) "seen" by consecutive measurements. Under such conditions the geometrical approximation for the tropospheric AMF (Eq. 9) is not valid. Thus, we decided to skip these observations, and only the blue points in Fig. 3 were used for the fitting of a low order polynomial to the measured values of $\operatorname{DSCD}_{\text {offset }}(t)$. Note that in cases of such localised plumes the measured DSCDs for different elevation angles typically become rather similar. Together with the use of AMF which are calculated for horizontally extended plumes (e.g. geometrical AMF), this leads to a systematic negative

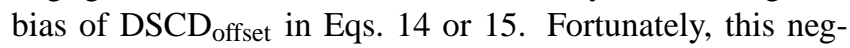
ative bias (together with the strong variation of $\operatorname{DSCD}_{\text {meas }}$ ) allows a clear identification and removal of measurements affected by localised plumes.

The resulting approximation of $\operatorname{DSCD}_{\text {offset }}(t)$ (black line in Fig. 3) shows a small decrease towards the evening, which probably indicates the increase of the stratospheric SCD with increasing SZA. From the scatter we estimate the uncertainty of an individual data point to about $1 \mathrm{e} 16 \mathrm{molec} / \mathrm{cm}^{2}$. Taking into account the total number of data points $(>100)$, this error reduces to $<1 \mathrm{e} 15 \mathrm{molec} / \mathrm{cm}^{2}$. For the $\mathrm{NO}_{2} \mathrm{VCD}$ retrieved from $22^{\circ}$ elevation angle $\left(\mathrm{AMF}_{\text {trop }} \approx 2.6\right)$, the corresponding error (of about $3 \mathrm{e} 14 \mathrm{molec} / \mathrm{cm}^{2}$ ) is negligible compared to other error sources (e.g. errors related to the geometric approximation or the influence of clouds).

The determined $\operatorname{DSCD}_{\text {offset }}(t)$ is inserted in Eq. 11 to derive the tropospheric $\mathrm{NO}_{2}$ VCDs (Fig. 4). Besides the values for the measurements at $22^{\circ}$ elevation angle (green), also those for the $40^{\circ}$ elevation angle (red) and $90^{\circ}$ elevation an- gle (black) are shown. Except the values close to the power plant, all three data sets show good quantitative agreement indicating the overall validity of our assumptions. Besides the (small) error in the determination of $\operatorname{DSCD}_{\text {offset }}(t)$, additional errors contribute to the overall uncertainty of the measurement, e.g. the signal to noise of the observations (can usually be neglected), the errors of the $\mathrm{NO}_{2}$ cross section (in the range of about $10 \%$ ), or the errors caused by the geometrical approximation. The latter was estimated from sensitivity studies to be typically $<15 \%$ for aerosol scenarios with optical depths up to 0.5 . Also the good agreement of the $\mathrm{NO}_{2} \mathrm{VCDs}$ derived from the different elevation angles indicate that this error is rather small for our measurements.

It should be noted here, that the AUTO-MAX-DOAS observations are only sensitive for the $\mathrm{NO}_{2}$ below the cloud cover. If substantial amounts of $\mathrm{NO}_{2}$ are located inside or above the cloud, AUTO-MAX-DOAS observations will underestimate the total tropospheric $\mathrm{NO}_{2} \mathrm{VCD}$.

Figure 5 shows the colour coded $\mathrm{NO}_{2} \mathrm{VCDs}$ for the Brussels-Heidelberg road measurements. As already seen in Fig. 4, the $\mathrm{NO}_{2}$ VCDs show some variations throughout the journey indicating the patterns of $\mathrm{NO}_{\mathrm{x}}$ sources. The highest values are found close to the Weissweiler power plant east of the Dutch border. High values occur also close to Koblenz and Mannheim/Heidelberg. The lowest values are found in the less populated region (Hundsrück mountains) south of Koblenz.

\subsection{Comparison with $\mathrm{NO}_{2}$ data from satellite observations}

One important application of mobile MAX-DOAS observations is the comparison with other data sets like model simulations and satellite observations. Mobile MAX-DOAS observations are able to resolve spatial scales in the range of 


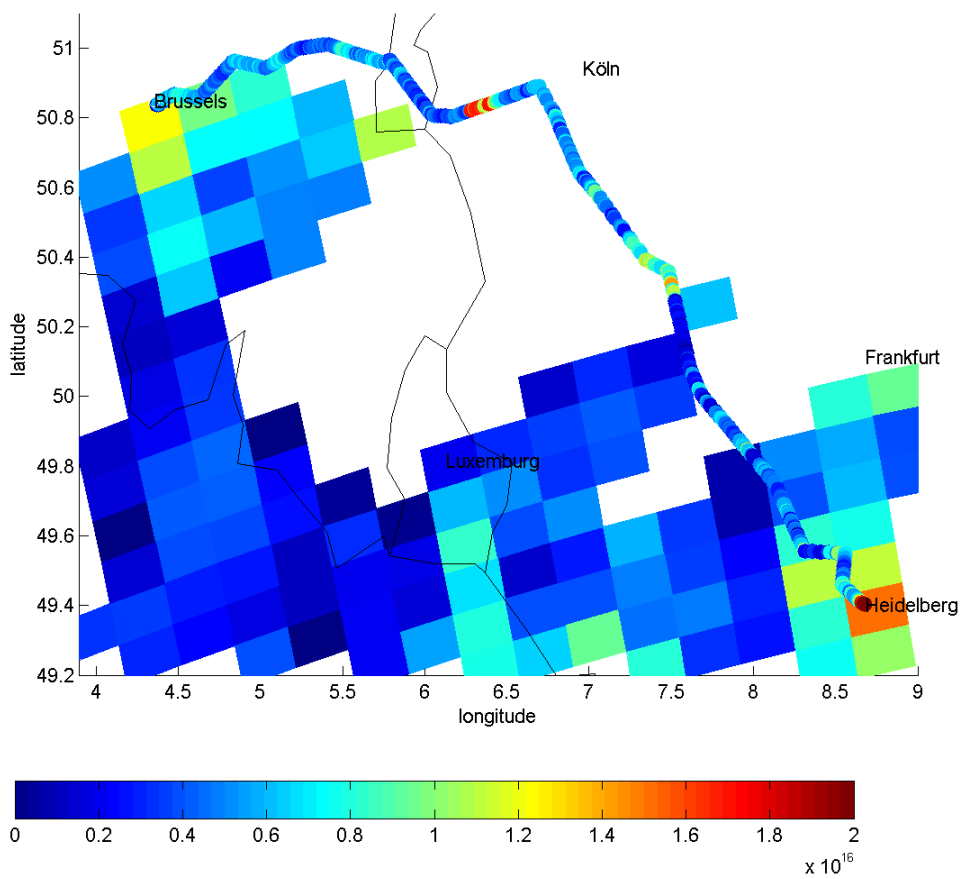

Fig. 5. Colour coded $\mathrm{NO}_{2}$ VCDs for the Brussels-Heidelberg road measurements on 5 September 2006 (derived from the $22^{\circ}$ elevation angle) and OMI tropospheric $\mathrm{NO}_{2}$ VCDs for the same day (DOMINO product from TEMIS, see http://www.temis.nl/airpollution/no2.html).

Table 1. Comparison of the tropospheric $\mathrm{NO}_{2}$ VCD from Auto MAX-DOAS and OMI for the three satellite ground pixels close to Brussels (see Fig. 5). OMI data are from www.temis.nl (DOMINO). OMI overpass is at $\sim$ 14:40 local time.

\begin{tabular}{|c|c|c|c|c|}
\hline \multirow[t]{2}{*}{$\begin{array}{l}\text { Center of } \\
\text { OMI pixel }\end{array}$} & \multirow[t]{2}{*}{$\begin{array}{l}\text { Time of car } \\
\text { measurements }\end{array}$} & \multicolumn{2}{|c|}{$\begin{array}{c}\text { Tropospheric } \mathrm{NO}_{2} \\
\text { VCD }\left[10^{15} \mathrm{molec} / \mathrm{cm}^{2}\right]\end{array}$} & \multirow[t]{2}{*}{ Cloud information } \\
\hline & & Car & OMI & \\
\hline $50.8^{\circ} \mathrm{N} 4.4^{\circ} \mathrm{E}$ & $13: 57-14: 40$ & $5.7 \pm 3$ & 12.3 & \multirow{3}{*}{$\begin{array}{l}\text { broken clouds along the driving route, satellite cloud fraction: } 9 \% \\
\text { clear sky along the driving route, satellite cloud fraction: } 7 \% \\
\text { clear sky along the driving route, satellite cloud fraction: } 4 \%\end{array}$} \\
\hline $50.85^{\circ} \mathrm{N} 4.7^{\circ} \mathrm{E}$ & $14: 40-14: 50$ & $5.9 \pm 3$ & 10.0 & \\
\hline $50.9^{\circ} \mathrm{N} 5.0^{\circ} \mathrm{E}$ & $14: 50-15: 03$ & $5.6 \pm 3$ & 7.5 & \\
\hline
\end{tabular}

kilometres and below and are thus especially well suited to investigate the effects of horizontal inhomogeneities of atmospheric trace gases on satellite retrievals.

While the main purpose of this study is to introduce a method for the retrieval of accurate high resolved tropospheric trace gas VCDs from mobile MAX-DOAS observations, in this section we also present a brief comparison of the retrieved tropospheric $\mathrm{NO}_{2}$ VCDs with satellite observations. Since the overpass time of the SCIAMACHY instrument on board ENVISAT (Bovensmann et al., 1999) is around 10:30 local time (more than $3 \mathrm{~h}$ before our MAX-DOAS measurements), no comparison to SCIAMACHY data was performed. In contrast, the overpass time of the OMI instrument on board AURA (Levelt et al., 2002) on that day (14:40 local time) matches the time of our observations for the first part after the start in Belgium. Thus we chose OMI data (DOMINO product from the TEMIS website, www.temis.nl) for comparison with our AUTO-MAX-
DOAS observations (see Fig. 5). A detailed comparison of the collocated observations at the beginning of the car measurements (see Table 1) yields only a fair agreement, with the OMI data being systematically higher than the AUTOMAX-DOAS measurements. Besides possible retrieval errors of both measurements, the differences might be related to the fact that the car measurements only cover the northern parts of the OMI pixels. Indications for a north-south gradient of the tropospheric $\mathrm{NO}_{2} \mathrm{VCD}$ are found from the car observations: they systematically yield higher values when the telescope (aligned with the driving direction) points slightly to the south. The differences between satellite and AUTOMAX-DOAS might also be related to the influence of clouds: they are largest for the OMI observations with higher cloud fraction. Future Auto-MAX-DOAS observations should be planned to ensure better spatio-temporal coincidence with satellite observations under mainly cloud-free conditions. 


\section{Conclusions}

We presented a new method for the analysis of MAX-DOAS observations from mobile platforms like cars or aircrafts. For such observations, the standard analysis techniques for MAX-DOAS observations can usually not be applied, because the probed airmasses can change rapidly between successive observations. Our new technique overcomes these problems and allows the exploitation of the full information content of mobile MAX-DOAS observations.

MAX-DOAS observations on mobile platforms yield (in addition to the vertical distribution) information on the horizontal variation of tropospheric trace gases. Such information is especially well suited for the quantitative comparison to model simulations and for the validation of tropospheric trace gas products from satellite observations. Our new technique allows to exploit the full potential of mobile MAXDOAS observations even in cases of small tropospheric trace gas concentrations and/or rather homogenous distributions.

In many cases, especially for Auto-MAX-DOAS, the tropospheric geometric approximation for the air mass factors can be used. However, for more complex viewing geometries (e.g. from aircraft), or in the case of strong aerosol scattering, also air mass factors derived from radiative transfer simulations can be used.

We apply the new technique to MAX-DOAS observations made during a car journey from Brussels to Heidelberg. We retrieve the distribution of the tropospheric $\mathrm{NO}_{2} \mathrm{VCD}$ along the driving route with a spatial resolution of about $1 \mathrm{~km}$. The results are consistent for all three used elevation angles $\left(22^{\circ}\right.$, $40^{\circ}$, and $90^{\circ}$ ) indicating that in this case the geometrical approximation is appropriate. The comparison with OMI satellite observations yields rather fair agreement (satellite observations are 25 to $100 \%$ larger than the AUTO-MAX-DOAS observations).

While our method is especially useful for MAX-DOAS observations from mobile platforms, it can of course also be applied to MAX-DOAS observations made at fixed locations. The effects of spatio-temporal variations of the trace gas field are much smaller compared to mobile observations. However, especially for high wind speeds and strong spatial gradients of the trace gas concentration field our method can clearly improve the quality of the results from fixed observations.
Acknowledgements. The authors thank Thorsten Stein and Roman Sinreich for their great support in the preparation of the instrument and assistance during the measurements. For the comparison with satellite observations OMI tropospheric $\mathrm{NO}_{2}$ VCDs from the TEMIS project were used (DOMINO product from www.temis.nl).

The service charges for this open access publication have been covered by the Max Planck Society.

Edited by: M. Van Roozendael

\section{References}

Brinksma, E. J., Pinardi, G., Volten, H., Braak, R., Richter, A., Schönhardt, A., van Roozendael, M., Fayt, C., Hermans, C., Dirksen, R. J., Vlemmix, T., Berkhout, A. J. C., Swart, D. P. J., Ötjen, H.,Wittrock, F.,Wagner, T., Ibrahim, O. W., de Leeuw, G. M., Moerman, R. L., Curier, E. A., Celarier, W. H., Cede, A., Knap, J. P., Veefkind, H. J., Eskes, M., Allaart, R., Rothe, A., Piters, J. M., and Levelt P. F.: The 2005 and 2006 DANDELIONS $\mathrm{NO}_{2}$ and Aerosol Validation Campaigns, J. Geophys. Res., 113, D16S46, doi:10.1029/2007JD008808, 2008.

Bogumil, K., Orphal, J., Homann, T., Voigt, S., Spietz, P., Fleischmann, O. C., Vogel, A., Hartmann, M., Bovensmann, H., Frerik, J., and Burrows, J. P.: Measurements of Molecular Absorption Spectra with the SCIAMACHY Pre-Flight Model: Instrument Characterization and Reference Data for Atmospheric Remote-Sensing in the 230-2380 nm Region, J. Photochem. Photobiol. A., 157, 167-1-84, 2003.

Bovensmann, H., Burrows, J. P., Buchwitz, M., Frerick, J., Noël, S., Rozanov, V. V., Chance, K. V., and Goede, A. H. P.: SCIAMACHY - Mission objectives and measurement modes, J. Atmos. Sci., 56(2), 127-150, 1999.

Bruns, M., Buehler, S. A., Burrows, J. P., Richter, A., Rozanov, A., Wang, P., Heue, K. P., Platt, U., Pundt, I., and Wagner, T.: $\mathrm{NO}_{2}$ Profile retrieval using airborne multi axis UV-visible skylight absorption measurements over central Europe, Atmos. Chem. Phys., 6, 3049-3058, 2006, http://www.atmos-chem-phys.net/6/3049/2006/.

Celarier, E. A., Brinksma, E. J., Gleason, J. F., Veefkind, J. P., Cede, A., Herman, J. R, Ionov, D., Goutail, F., Pommereau, JP., Lambert, J-C., van Roosendael M., Pinardi, G., Wittrock, F., Schönhardt, A., Richter, A., Ibrahim, O.W., Wagner, T., Bojkov, B., Mount, G., Spinei, E., Chen, C. M., Pongetti, T. J., Sander, S. P., Bucsela, E. J., Wenig, M. O., Swart, D. P. J., Volten, H., Kroon, M., and Levelt, P. F.: Validation of Ozone Monitoring Instrument Nitrogen Dioxide Columns, J. Geophys. Res., 113, D15S15, doi:10.1029/2007JD008908, 2008.

Dix, B., Brenninkmeijer, C. A. M., Frieß, U., Wagner, T., and Platt, U.: Airborne multi-axis DOAS measurements of atmospheric trace gases on CARIBIC long-distance flights, Atmos. Meas. Tech. Discuss., 2, 265-301, 2009,

http://www.atmos-meas-tech-discuss.net/2/265/2009/. 
Fayt, C., Van Roozendael, M., WinDOAS 2.1 Software User Manual, (available at: http://www.oma.be/GOME/GOMEBrO/ WinDOAS-SUM-210b.pdf), 2001.

Fietkau, S., Medeke, T., Richter, A., Sheode, N., Sinnhuber, B.-M., Wittrock, F., Theys, N., van Roozendael, M., and Burrows, J. P.: Ground-based measurements of tropospheric and stratospheric bromine monoxide above Nairobi $\left(1^{\circ} \mathrm{S}, 36^{\circ} \mathrm{E}\right)$, Atmos. Chem. Phys. Discuss., 7, 6527-6555, 2007, http://www.atmos-chem-phys-discuss.net/7/6527/2007/.

Frieß, U., Monks, P. S., Remedios, J. J., Rozanov, A., Sinreich, R., Wagner, T., and Platt, U.: MAX-DOAS $\mathrm{O}_{4}$ measurements: A new technique to derive information on atmospheric aerosols (II), Modelling studies, J. Geophys. Res., 111, D14203, doi:10.1029/2005JD006618, 2006.

Grainger, J. F. and Ring, J.: Anomalous Fraunhofer line profiles, Nature, 193, 762, 1962.

Greenblatt, G. D., Orlando, J. J., Burkholder, J.,B., and Ravishankara, A. R.: Absorption measurements of oxygen between 330 and 1140 nm, J. Geophys. Res., 95, 18577-18582, 1990.

Heckel, A., Richter, A., Tarsu, T., Wittrock, F., Hak, C., Pundt, I., Junkermann, W., and Burrows, J. P.: MAX-DOAS measurements of formaldehyde in the Po-Valley, Atmos. Chem. Phys., 5, 909918, 2005, http://www.atmos-chem-phys.net/5/909/2005/.

Herman, J., Cede, A., Spinei, E., Mount, G., Tzortziou, M., and Abuhassan, N.: NO column amounts from ground-based Pandora and MFDOAS spectrometers using the direct-sun DOAS technique, Intercomparisons and application to OMI validation, J. Geophys. Res., 114, D13307, doi:10.1029/2009JD011848, 2009.

Heue, K.-P., Richter, A., Bruns, M., Burrows, J. P., v. Friedeburg, C., Platt, U., Pundt, I., Wang, P., and Wagner, T.: Validation of SCIAMACHY tropospheric $\mathrm{NO}_{2}$-columns with AMAXDOAS measurements, Atmos. Chem. Phys., 5, 1039-1051, 2005, http://www.atmos-chem-phys.net/5/1039/2005/.

Hönninger G. and Platt, U.: Observations of $\mathrm{BrO}$ and its vertical distribution during surface ozone depletion at Alert, Atmos. Environ., 36, 2481-2490, 2002.

Hönninger, G., von Friedeburg, C., and Platt, U.: Multi axis differential optical absorption spectroscopy (MAX-DOAS), Atmos. Chem. Phys., 4, 231-254, 2004, http://www.atmos-chem-phys.net/4/231/2004/.

Hönninger G., Leser H., Sebastian O., and Platt U., Ground-based Measurements of Halogen Oxides at the Hudson Bay by Active Long Path DOAS and Passive MAX-DOAS, Geophys. Res. Lett. 31, L04111, doi:10.1029/2003GL018982, 2004b.

Ibrahim, O. W.: Applications on Ground-based Tropospheric Measurements using Multi-Axis Differential Optical Absorption Spectroscopy, $\mathrm{PhD}$-thesis, University of Heidelberg, Germany, 2009.

Irie, H., Kanaya, Y., Akimoto, H., Tanimoto, H., Wang, Z., Gleason, J. F., and Bucsela, E. J.: Validation of OMI tropospheric $\mathrm{NO}_{2}$ column data using MAX-DOAS measurements deep inside the North China Plain in June 2006: Mount Tai Experiment 2006, Atmos. Chem. Phys., 8, 6577-6586, 2008, http://www.atmos-chem-phys.net/8/6577/2008/.

Johansson, M., Galle, B., Yu, T., Tang, L., Chen, D., Li, H., Li, J. X., and Zhang, Y.: Quantification 20 of total emission of air pollutants from Beijing using mobile mini-DOAS, Atmos. Environ.,
42, 6926-6933, 2008.

Johansson, M., Rivera, C., de Foy, B., Lei, W., Song, J., Zhang, Y., Galle, B., and Molina, L.: Mobile mini-DOAS measurement of the emission of $\mathrm{NO}_{2}$ and $\mathrm{HCHO}$ from Mexico City, Atmos. Chem. Phys. Discuss., 9, 865-882, 2009,

http://www.atmos-chem-phys-discuss.net/9/865/2009/.

Kraus, DOASIS, A Framework Design for DOAS, PhD-thesis, University of Mannheim, available at: http://hci.iwr.uni-heidelberg. de/publications/dip/2006/Kraus_PhD2006.pdf, 2006.

Kurucz, R. L., Furenlid, I., Brault, J., and Testerman, L.: Solar flux atlas from $296 \mathrm{~nm}$ to $1300 \mathrm{~nm}$, National Solar Observatory Atlas No. 1, 1984.

Leser, H., Hönninger, G., and Platt, U.: MAX-DOAS measurements of $\mathrm{BrO}$ and $\mathrm{NO}_{2}$ in the marine boundary layer, Geophys. Res. Lett., 30, 10, doi:10.1029/2002GL015811, 2003.

Levelt, P. F. and Noordhoek, R.: OMI Algorithm Theoretical Basis Document Volume I: OMI Instrument, Level 0-1b Processor, Calibration \& Operations, Tech. Rep. ATBD-OMI-01, Version 1.1, August 2002.

Marquard, L. C., Wagner, T., and Platt, U.: Improved Air Mass Factor Concepts for Scattered Radiation Differential Optical Absorption Spectroscopy of Atmospheric Species, J. Geophys. Res., 105, 1315-1327, 2000.

Noxon, J. F., Whipple, E. C., and Hyde, R. S.: Stratospheric $\mathrm{NO}_{2}$. 1. Observational method and behaviour at midlatitudes, J. Geophys. Res., 84, 5047-5076, 1979.

Perliski, L. M. and Solomon, S.: On the evaluation of air mass factors for atmospheric near-ultraviolet and visible absorption spectroscopy, J. Geophys. Res., 98, 10363-10374, 1993.

Platt, U. and Stutz, J.: Differential Optical Absorption Spectroscopy, Principles and Applications, Springer, Berlin, 2008.

Rothman, L. S., Jacquemart, D., Barbe, A., Benner, D. C., Birk, M., Brown, L. R., Carleer, M. R., Chackerian Jr., C., Chance, K., Coudert, L. H., Dana, V., Devi, V. M., Flaud, J.-M., Gamache, R. R., Goldman, A., Hartmann, J.-M., Jucks, K. W., Maki, A. G., Mandin, J.-Y., Massie, S. T., Orphal, J., Perrin, A., Rinsland, C. P., Smith, M. A. H., Tennyson, J., Tolchenov, R.,N., Toth, R. A., Vander Auwera, J., Varanasi, P., Wagner, G.: The HITRAN 2004 molecular spectroscopic database, J. Quant. Spectrosc. Ra., 96, 139-204, 2005.

Sinreich, R., Frieß, U., Wagner, T., and Platt, U.: Multi axis differential optical absorption spectroscopy (MAX-DOAS) of gas and aerosol distributions, Faraday Discuss., 130, doi:10.1039/b419274, 2005.

Solomon, S., Schmeltekopf, A. L., and Sanders, R. W.: On the interpretation of zenith sky absorption measurements, J. Geophys. Res., 92, 8311-8319, 1987.

Stutz, J. and Platt, U.: Numerical Analyses and Estimation of the Statistical Error of Differential Optical Absorption Spectroscopy Measurements with Least Square Methods, Appl. Opt., 35, 6041-6053, 1996.

Theys, N., Van Roozendael, M., Hendrick, F., Fayt, C., Hermans, C., Baray, J.-L., Goutail, F., Pommereau, J.-P., and De Mazière, M.: Retrieval of stratospheric and tropospheric $\mathrm{BrO}$ columns from multi-axis DOAS measurements at Reunion Island $\left(21^{\circ} \mathrm{S}\right.$, $56^{\circ}$ E), Atmos. Chem. Phys., 7, 4733-4749, 2007, http://www.atmos-chem-phys.net/7/4733/2007/.

Vandaele, A. C., Hermans, C., Simon, P. C., Carleer, M., Colin, R., Fally, S., Mérienne, M. F., Jenouvrier, A., and Coquart, B.: Mea- 
surements of the $\mathrm{NO}_{2}$ Absorption Cross-section from $42000 \mathrm{~cm}$ 1 to $10000 \mathrm{~cm}-1(238-1000 \mathrm{~nm})$ at $220 \mathrm{~K}$ and $294 \mathrm{~K}$, J. Quant. Spectrosc. Radiat. Transfer, 59, 171-184, 1997.

Van Roozendael, M., Fayt, C., Post, P., Hermans, C., and Lambert, J.-C.: Retrieval of $\mathrm{BrO}$ and $\mathrm{NO}_{2}$ from UV-Visible Observations, in: Sounding the troposphere from space: a new era for atmospheric chemistry, Springer-Verlag, ISBN 3-540-40873-8, edited by Borrell, P. M., Burrows, J. P., Platt, U., et al., 2003.

Volk, R., Auto-MAX-DOAS, Diploma thesis, University of Heidelberg, 2008.

Wagner, T., Dix, B., v. Friedeburg, C., Frieß, U., Sanghavi, S., Sinreich, R., and Platt, U.: MAX-DOAS $\mathrm{O}_{4}$ measurements: A new technique to derive information on atmospheric aerosols - Principles and information content, J. Geophys. Res., 109, D22205, doi:10.1029/2004JD004904, 2004.

Wagner, T., Burrows, J. P., Deutschmann, T., Dix, B., von Friedeburg, C., Frieß, U., Hendrick, F., Heue, K.-P., Irie, H., Iwabuchi, H., Kanaya, Y., Keller, J., McLinden, C. A., Oetjen, H., Palazzi, E., Petritoli, A., Platt, U., Postylyakov, O., Pukite, J., Richter, A., van Roozendael, M., Rozanov, A., Rozanov, V., Sinreich, R., Sanghavi, S., and Wittrock, F.: Comparison of box-airmass-factors and radiances for Multiple-Axis Differential Optical Absorption Spectroscopy (MAX-DOAS) geometries calculated from different UV/visible radiative transfer models, Atmos. Chem. Phys., 7, 1809-1833, 2007,

http://www.atmos-chem-phys.net/7/1809/2007/.
Wagner, T., Ibrahim, O., Sinreich, R., Frieß, U., von Glasow, R., and Platt, U.: Enhanced tropospheric BrO over Antarctic sea ice in mid winter observed by MAX-DOAS on board the research vessel Polarstern, Atmos. Chem. Phys., 7, 3129-3142, 2007, http://www.atmos-chem-phys.net/7/3129/2007/.

Wagner, T., Deutschmann, T., and Platt, U.: Determination of aerosol properties from MAX-DOAS observations of the Ring effect, Atmos. Meas. Tech., 2, 495-512, 2009, http://www.atmos-meas-tech.net/2/495/2009/.

Wang, P., Richter, A., Bruns, M., Rozanov, V. V., Burrows, J. P., Heue, K.-P., Wagner, T., Pundt, I., and Platt, U.: Measurements of tropospheric $\mathrm{NO}_{2}$ with an airborne multi-axis DOAS instrument, Atmos. Chem. Phys., 5, 337-343, 2005, http://www.atmos-chem-phys.net/5/337/2005/.

Wang, P., Richter, A., Bruns, M., Burrows, J. P., Scheele, R., Junkermann, W., Heue, K.-P., Wagner, T., Platt, U., and Pundt, I.: Airborne multi-axis DOAS measurements of tropospheric $\mathrm{SO}_{2}$ plumes in the Po-valley, Italy, Atmos. Chem. Phys., 6, 329-338, 2006, http://www.atmos-chem-phys.net/6/329/2006/.

Wittrock, F., Oetjen, H., Richter, A., Fietkau, S., Medeke, T., Rozanov, A., and Burrows, J. P.: MAX-DOAS measurements of atmospheric trace gases in Ny-Ålesund - Radiative transfer studies and their application, Atmos. Chem. Phys., 4, 955-966, 2004, http://www.atmos-chem-phys.net/4/955/2004/. 